\title{
Effect of midkine on gemcitabine resistance in biliary tract cancer
}

\author{
YONGLIANG LU ${ }^{1 *}$, BING YAN $^{2 *}$, HUIHUI GUO ${ }^{3}$, LI QIU $^{2}$, XINRONG SUN ${ }^{4}$, \\ XIANG WANG ${ }^{3}$, QIAN SHI $^{3}$ and YING BAO $^{4}$ \\ ${ }^{1}$ Department of Medicine, Huzhou University; Departments of ${ }^{2}$ Pharmacy, ${ }^{3}$ Laboratory Medicine and ${ }^{4}$ Surgery, \\ The First Affiliated Hospital of Huzhou University, The First People's Hospital of Huzhou, \\ Huzhou, Zhejiang 313000, P.R. China
}

Received May 17, 2017; Accepted January 4, 2018

DOI: $10.3892 /$ ijmm.2018.3399

\begin{abstract}
Gemcitabine-based chemotherapy is one of the most effective and commonly used chemotherapeutic regimens for biliary tract cancer (BTC). However, development of resistance to this drug limits its efficacy. The present study aimed to explore the effects of midkine (MDK) on the resistance of BTC cells to gemcitabine. Cell viability and proliferation were measured by a Cell Counting Kit-8 assay and 5-ethynyl-2'-deoxyuridine staining, respectively. Western blot analysis was used to detect the expression of E-cadherin and vimentin. The results indicated that BTC cell lines were more resistant to gemcitabine plus MDK compared with gemcitabine alone. In terms of the underlying mechanism, MDK promoted the epithelial to mesenchymal transition (EMT) of BTC cells and the enhancing effect of MDK on gemcitabine resistance was abrogated when the EMT was blocked with small interfering (si)RNA targeting Twist. In addition, MDK promoted the expression of Notch-1, while knockdown of Notch-1 by siRNA blocked the EMT process in the BTC cell lines. Taken together, these results indicated that MDK promoted gemcitabine resistance of BTC through inducing EMT via upregulating Notch-1. It was suggested that inhibition of the EMT is a promising strategy to overcome MDK-induced drug resistance.
\end{abstract}

\section{Introduction}

Biliary tract cancer (BTC) refers to a group of cancers of the biliary tract, including gallbladder cancer, cholangiocarcinoma of intrahepatic and extrahepatic bile ducts, and cancers of

Correspondence to: Professor Ying Bao, Department of Surgery, The First Affiliated Hospital of Huzhou University, The First People's Hospital of Huzhou, 158 Guangchanghou Road, Huzhou, Zhejiang 313000, P.R. China

E-mail: baoying2222@126.com

*Contributed equally

Key words: midkine, gemcitabine, epithelial mesenchymal transition, Notch-1, drug resistance the ampulla and papilla of Vater $(1,2)$. The incidence rate of BTC differs among geographic areas: It is high in Asia, Latin America and eastern European countries, while it is low in the US and certain western European countries (2). Complete resection has been considered the best treatment for BTC; however, most patients are ineligible for surgery due to its rapid progression and non-specific symptoms (3-5). Even patients who are treated with surgery have a poor prognosis.

Although surgery remains the only curative treatment option, chemotherapy prolongs the survival of patients with BTC $(6,7)$. Among the chemotherapeutic drugs, gemcitabine and cisplatin have proven to be the most effective first-line drugs (8-10). However, drug resistance to gemcitabine limits its effect, and the median overall survival of patients with advanced BTC who receive chemotherapy is only $\sim 1$ year (11). Therefore, it is essential to explore the potential mechanism underlying the resistance of BTC to gemcitabine in order to enhance its effect and prolong patient survival.

Midkine (MDK), a heparin-binding growth factor, was first identified as a highly expressed factor involved in embryonic development (12). MDK has been reported to have important roles in the survival, growth and migration of cells, which may contribute to oncogenesis and tumor progression in numerous types of cancer (13-18). Several studies have demonstrated that MDK mediates drug resistance. Mirkin et al (19) employed a cytokine complementary DNA array to identify putative survival molecules in human neuroblastoma and osteosarcoma cells and identified MDK as a lead candidate responsible for doxorubicin resistance via regulation of the AKT pathway. Furthermore, Lorente et al (20) identified MDK as a pivotal factor involved in the resistance of glioma cells to the pro-autophagic and anti-tumoral action of tetrahydrocannabinol by regulation of the anaplastic lymphoma kinase receptor. Xu et al (21) proved that MDK, which activates AKT and extracellular signal-regulated kinase by phosphorylation, induced doxorubicin resistance in gastric cancer cells. $\mathrm{Hu}$ et al (22) indicated that MDK increased the drug-efflux ability in lymphoblastic leukemia, thereby having an important role in multidrug resistance. These results highlighted the fact that MDK may have an essential role in cancer chemotherapy resistance. However, the role of MDK in the drug resistance of BTC has remained largely elusive.

Epithelial to mesenchymal transition (EMT) is the process wherein epithelial cells lose their apical-basal polarity and 
cell-cell adhesion and transit to invasive mesenchymal cells. EMT cells exhibit decreased expression of epithelial genes (e.g., E-cadherin) and increased expression of mesenchymal genes (e.g., vimentin) (23). The link between EMT and drug resistance of cancer cells has been suggested in a previous study. Furthermore, increasing evidence has indicated that drug resistance of several cancer types, including lung (24), pancreatic (25), liver (26) and breast cancer (27), is frequently accompanied by EMT. In BTC, EMT involves the invasion and migration of BTC cells. However, evidence supporting the role of EMT in drug resistance of BTC has remained insufficient.

Therefore, the present study aimed to determine the association between MDK, EMT and gemcitabine resistance in BTC and explore the potential mechanisms underlying gemcitabine resistance.

\section{Materials and methods}

Cell culture and reagents. Two human BTC cell lines, RBE and GBC-SD, were purchased from the American Type Culture Collection (Manassas, VA, USA) and cultured according to the supplier's recommendation in RPMI-1640 medium (Gibco; Thermo Fisher Scientific, Inc., Waltham, MA, USA) supplemented with $10 \%$ fetal bovine serum (Gibco; Thermo Fisher Scientific, Inc.) and maintained at $37^{\circ} \mathrm{C}$ in a humidified atmosphere of air with $5 \% \mathrm{CO}_{2}$. For hypoxia culture, cells were maintained at $37^{\circ} \mathrm{C}$ in a humidified atmosphere with $5 \% \mathrm{CO}_{2}, 1 \% \mathrm{O}_{2}$ and $94 \% \mathrm{~N}_{2}$. MDK was from Sigma-Aldrich (cat. no. SRP3114; Merck KGaA, Darmstadt, Germany) and was used at a concentration of $50 \mathrm{ng} / \mathrm{ml}$. Gemcitabine (cat. no. S1714) was purchased from Selleck Chemicals (Houston, TX, USA).

Cell viability assay. RBE and GBC-SD cells were seeded into 96-well microplates at a density of 5,000 cells/well and cultured with different concentrations of gemcitabine ranging from 0.00 to $0.06 \mu \mathrm{g} / \mathrm{ml}$, MDK (50 $\mathrm{ng} / \mathrm{ml}$ ) or a combination of the two drugs for $48 \mathrm{~h}$. Cell viability was detected using the Cell Counting Kit-8 (CCK-8) assay (Dojindo, Kumamoto, Japan) according to the manufacturer's protocol. In brief, $100 \mu \mathrm{l}$ medium and $10 \mu \mathrm{l} \mathrm{CCK-8} \mathrm{solution} \mathrm{were} \mathrm{added} \mathrm{to} \mathrm{microplates,}$ and the cells were incubated for $2 \mathrm{~h}$. The optical density at $450 \mathrm{~nm}$ was determined using a MRX II microplate reader (Dynex, Chantilly, VA, USA). Cell viability in each group was determined by comparison with untreated control cells.

Cell proliferation assay. Cell proliferation was analyzed by 5-ethynyl-2'-deoxyuridine (EdU) staining using the Click-iTEdU Imaging kit (Invitrogen; Thermo Fisher Scientific, Inc.) following the manufacturer's protocol. RBE or GBC-SD cells were treated with gemcitabine alone or a combination of gemcitabine $(0.03136 \mu \mathrm{g} / \mathrm{ml}$ for RBE; $0.1433 \mu \mathrm{g} / \mathrm{ml}$ for GBC-SD) and MDK (50 ng/ml) for $48 \mathrm{~h}$, and then exposed to $10 \mu \mathrm{MEdU}$ for $2 \mathrm{~h}$ at $37^{\circ} \mathrm{C}$. The cells were then fixed with $3.7 \%$ formaldehyde for $15 \mathrm{~min}$ at room temperature and treated with $0.5 \%$ Triton X-100 (Sangon Biotech, Shanghai, China) for $20 \mathrm{~min}$ at room temperature for permeabilization. After washing twice with PBS containing 3\% bovine serum albumin, the cells were treated with $0.5 \mathrm{ml}$ of Click-iT ${ }^{\circledR}$ reaction cocktail (Invitrogen; Thermo Fisher Scientific, Inc.) for 30 min in the dark. Subsequently, the cell DNA was stained with $1 \mathrm{ml} 1 \mathrm{X}$ Hoechst 33342 (1:2,000 dilution) for $30 \mathrm{~min}$. Finally, three random fields of view per slide were selected under a fluorescence microscope (Olympus, Tokyo, Japan), and the number of proliferative (EdU-positive) cells was counted.

Cell transfection for RNA interference. Human Twist small interfering RNA (siRNA) was synthesized by Shanghai GeneChem Co., Ltd. (Shanghai, China). The human Twist siRNA sequence was as follows: Twist1, 5'-GGUGUCUAA AUGCAUUCAUTT-3' and 5'-AUGAAUGCAUUUAGACAC CTT-3'; Notch1, 5'-CCAACCCUGUCAAUGGCAATT-3' and 5'-UUGCCAUUGACAGGGUUGGTT-3'; Scrambled siRNA, 5'-UUCUCCGAACGUGUCACGUTT-3' and 5'-ACGUGA CACGUUCGGAGAATT-3'. The transfection was performed by using Lipofectamine 2000 (Invitrogen; Thermo Fisher Scientific, Inc.) according to the manufacturer's protocol.

Western blot analysis. The interference efficiency of Twist siRNA and its effect on the expression of various proteins was determined by western blot analysis (28). The following antibodies were used: Anti-E-cadherin (cat.no.3195), anti-vimentin (cat. no. 5741), anti-Twist (cat. no. 46702), anti- $\beta$-actin (cat. no. 8457) (all at 1:1,000 dilution; Cell Signaling Technology, Inc., Danvers, MA, USA) and anti-Notch-1 (cat. no. ab8925; 1:1,000 dilution; Abcam, Cambridge, UK). The corresponding secondary antibodies conjugated to horseradish peroxidase (cat. no. ab98489; 1:2,000 dilution) were obtained from Abcam. The grey value was analyzed by QuantityOnev. 4.62 software (Bio-Rad Laboratories, Inc., Hercules, CA, USA).

Statistical analysis. Three independent experiments were performed for each experiment. Experimental data were expressed as the mean \pm standard deviation. Analyses were performed using GraphPad Prism 5 (GraphPad Software, Inc.,La Jolla, CA, USA). Comparisons among datasets were performed by using one-way analysis of variance followed by Tukey's post hoc test or a unpaired Student's t-test. $\mathrm{P}<0.05$ was considered to indicate a statistically significant difference.

\section{Results}

MDK induces gemcitabine resistance in BTC cells. To determine whether MDK is involved in gemcitabine resistance of BTC, the effect of MDK on BTC cell viability was evaluated in the presence of different concentrations of gemcitabine. BTC cells exhibited higher cell viability after gemcitabine + MDK treatment than cells treated with gemcitabine alone (Fig. 1A and B). In addition, the EdU assay indicated that BTC cells had increased proliferation in the presence of gemcitabine and MDK compared with gemcitabine alone, which suggests that MDK induces gemcitabine resistance in BTC (Fig. 1C and D).

EMT is involved in gemcitabine resistance of BTC cells. The EMT is known to be associated with chemoresistance of cancers, and MDK was reported to induce EMT in several cancer types (29-31). Thus, the present study hypothesized that EMT may be involved in gemcitabine resistance in BTC and that MDK may promote gemcitabine resistance in BTC by regulating the EMT pathway. To prove this hypothesis, 

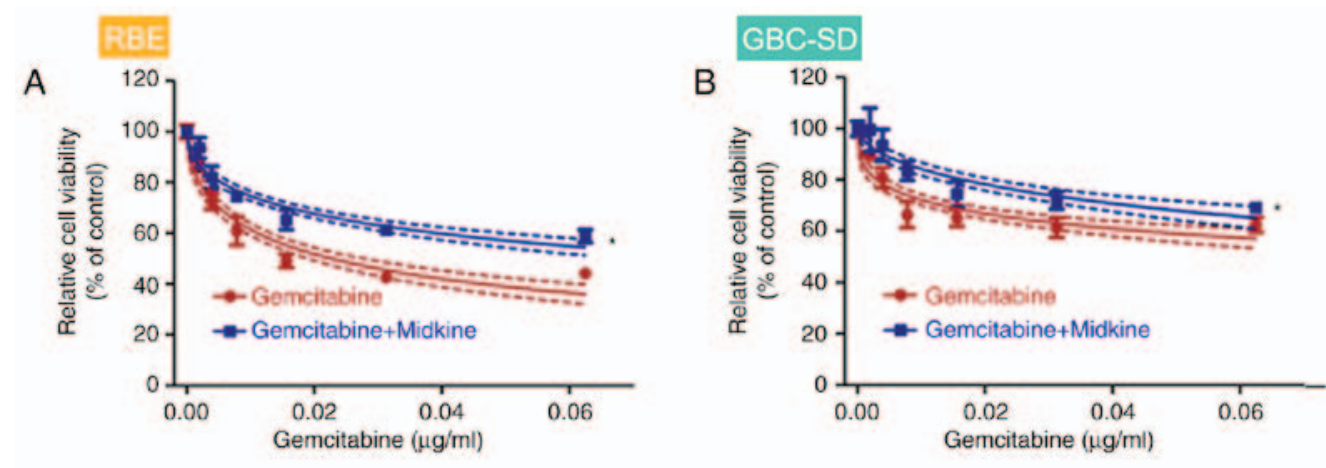

C
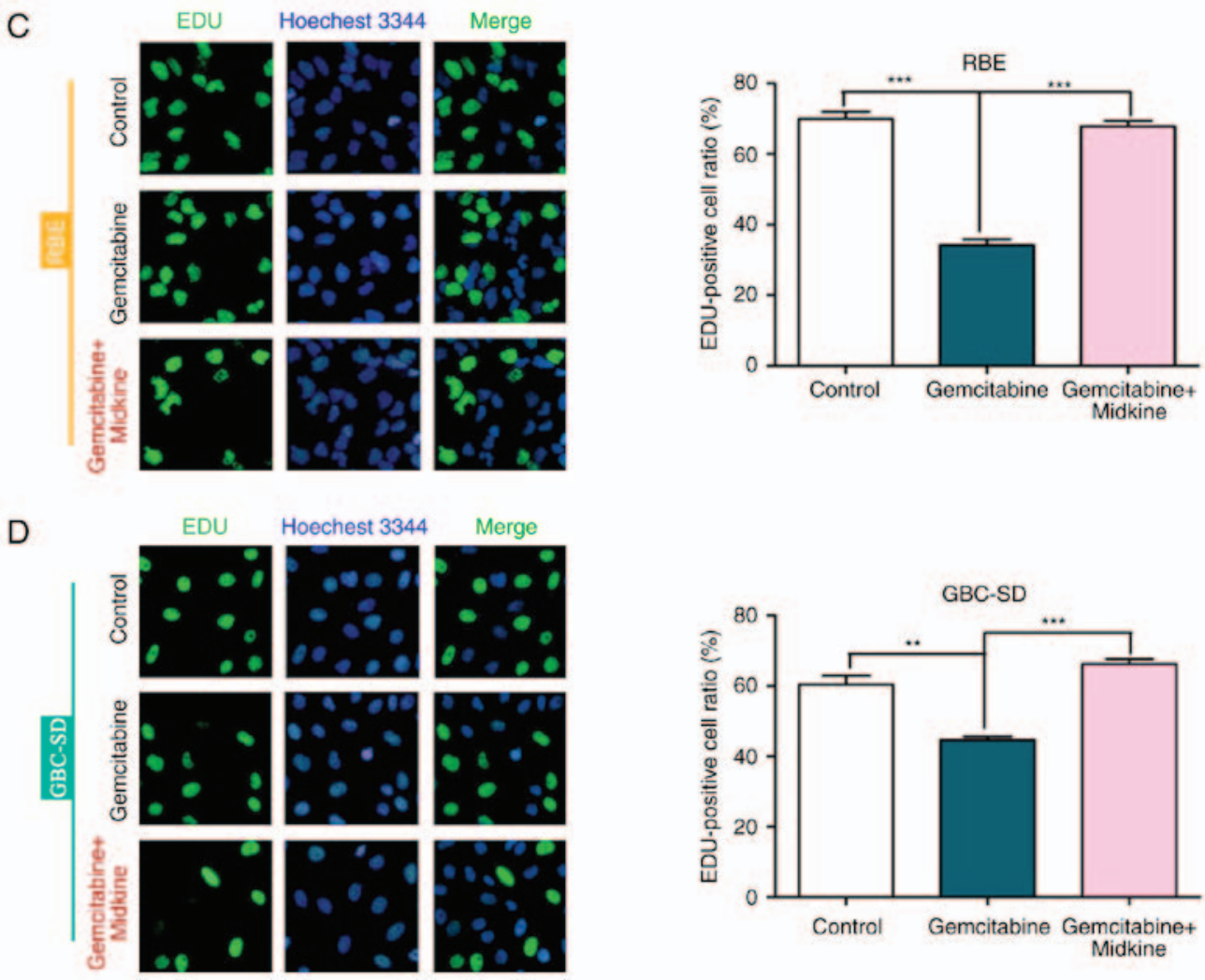

Figure 1. Comparison of BTC cell viability and proliferation with or without midkine in the presence of gemcitabine. Effect of midkine on the viability of (A) RBE and (B) GBC-SD cells cultured with different concentrations of gemcitabine ( $0.00,0.02,0.04$ or $0.06 \mu \mathrm{g} / \mathrm{ml})$ for $48 \mathrm{~h}$. " $\mathrm{P}<0.05 \mathrm{vs}$. Gemcitabine. (C) The cell proliferation rate was determined by an EdU assay. RBE cells were cultured with gemcitabine (RBE, $0.03136 \mu \mathrm{g} / \mathrm{ml}$ ) or in combination with $50 \mathrm{ng} / \mathrm{ml}$ midkine (RBE, $0.03136 \mu \mathrm{g} / \mathrm{ml}$ ) or vehicle. Cell nuclei were stained with Hoechst33344 (blue) (x200 magnification). The number of EdU-positive cells (green) was counted. ${ }^{* * *} \mathrm{P}<0.001$ with comparisons shown by lines. (D) GBC-SD cells were cultured with gemcitabine (GBC-SD, $\left.0.1433 \mu \mathrm{g} / \mathrm{ml}\right)$ or in combination with $50 \mathrm{ng} / \mathrm{ml}$ midkine (GBC-SD, $0.1433 \mu \mathrm{g} / \mathrm{ml}$ gemcitabine) or vehicle. Cell nuclei were stained with Hoechst33344 (blue) (x200 magnification). The number of EdU-positive cells (green) were counted. ${ }^{* * *} \mathrm{P}<0.01$ and ${ }^{* * *} \mathrm{P}<0.001$ with comparisons shown by lines.

the efficiency of gemcitabine on the two BTC cell lines was first examined. The CCK-8 assay indicated that gemcitabine effectively inhibited the viability of BTC cells in a concentration-dependent manner. Of note, the BTC cell line RBE was more sensitive to gemcitabine than the GBC-SD cell line (Fig. 2A). Subsequently, the expression of the epithelial marker E-cadherin and the mesenchymal marker vimentin was assessed in these two cell lines, revealing that the cell line RBE had high E-cadherin levels, but low vimentin levels, whereas the opposite results were observed in the GBC-SD cell line (Fig. 2B). Accordingly, the present results indicate that EMT may be involved in gemcitabine resistance in BTC.

To confirm this result, the BTC cell lines were exposed to hypoxic conditions to induce EMT, as reported previously $(32,33)$. The results demonstrated that hypoxia upregulated the expression of vimentin and downregulated the expression of E-cadherin in BTC cell lines, thereby promoting EMT (Fig. 3A). As expected, BTC cell viability increased in the presence of gemcitabine under hypoxic conditions compared with that under normoxic conditions (Fig. 3B and C). In addition, gemcitabine treatment led to an upregulation of the expression of vimentin and a downregulation of the expression of E-cadherin in the BTC cell lines under normoxia conditions (Fig. 3D). To confirm the role of the EMT in gemcitabine resistance, Twist, a key regulator of EMT (34), was knocked down to block EMT in BTC cell lines. The results demonstrated that the BTC cell lines became more sensitive to gemcitabine after Twist inhibition (Fig. 3E and F). Interference efficiency of Twistl was measured using western blot analysis (Fig. 3G). 


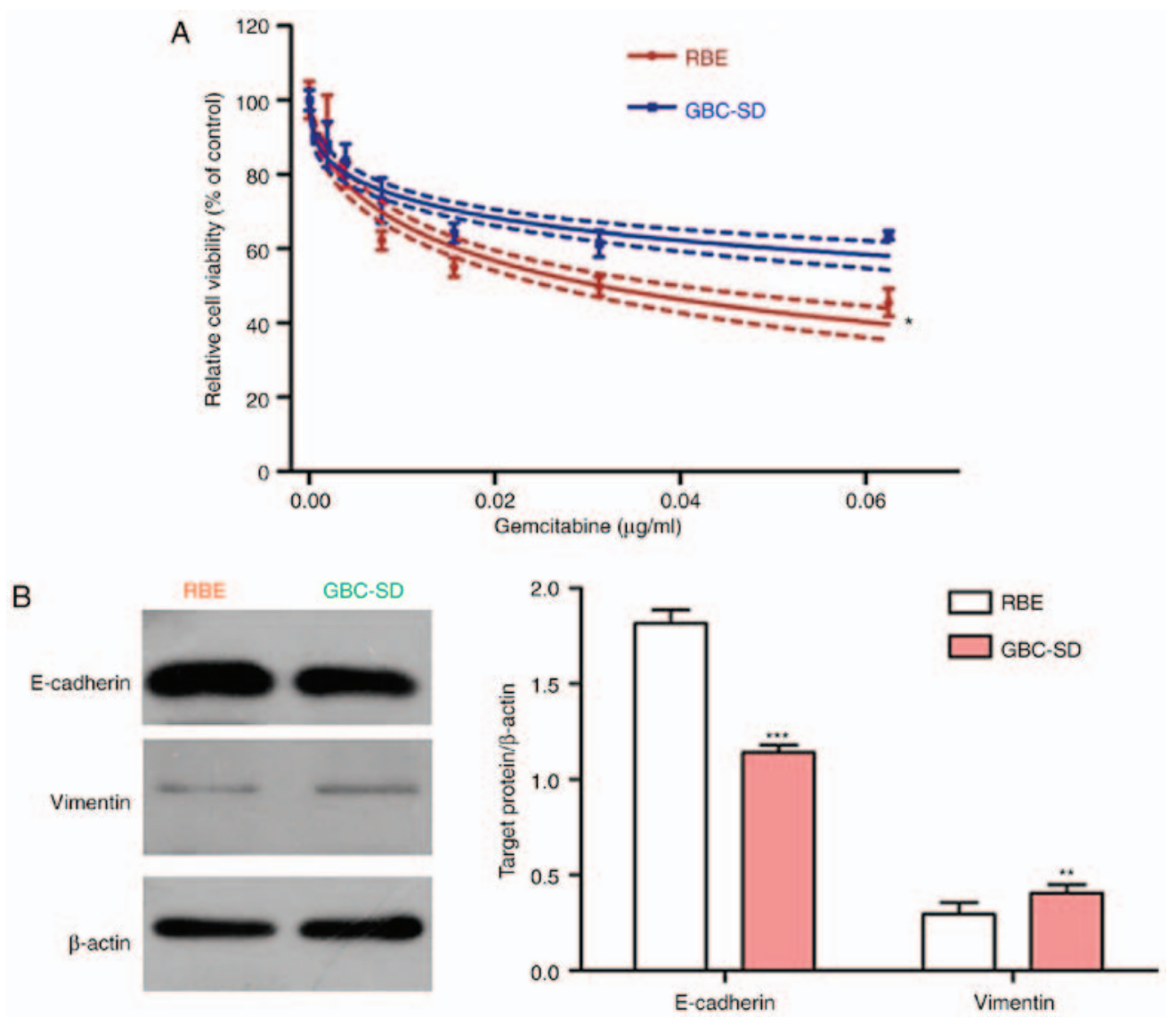

Figure 2. Effects of gemcitabine on cell viability and the expression of E-cadherin and vimentin in biliary tract cancer cell lines. (A) Comparison of the cell viability of GBC-SD and RBE cell lines cultured with different concentrations of gemcitabine was examined using the Cell Counting Kit- 8 assay. " $\mathrm{P}<0.05$ vs. GBC-SD. (B) Expression of E-cadherin and vimentin in GBC-SD and RBE cell lines determined by western blot analysis. $\beta$-actin was used as the internal control, and the average grey values are presented in a histogram. ${ }^{* *} \mathrm{P}<0.01$ and ${ }^{* * * *} \mathrm{P}<0.001$ vs. $\mathrm{RBE}$.

Therefore, the present results indicated that gemcitabine resistance in BTC may be mediated via the EMT.

MDK mediates gemcitabine resistance in BTC cells by regulating EMT. To further prove the abovementioned hypothesis, the association between MDK and EMT in gemcitabine resistance was examined. First, the expression of E-cadherin and vimentin was detected in the two BTC cell lines cultured in the presence of MDK. The results indicated that MDK treatment led to a significant upregulation of vimentin expression and a downregulation of E-cadherin expression in BTC cell lines (Fig. 4). Thereafter, the efficiency of MDK to induce gemcitabine resistance was examined after EMT blockage. To block EMT, Twist, the key molecule in the EMT pathway, was inhibited using siRNA. The knockdown efficiency of Twist siRNA was confirmed by western blot (Fig. 5A). As expected, cells transfected with scrambled siRNA were more sensitive to treatment with gemcitabine compared with those in the MDK+scrambled siRNA group, and after EMT inhibition with Twist siRNA, the effect of MDK to induce gemcitabine resistance in BTC cells was lost (Fig. 5B and C). Hence, the present results proved the hypothesis that MDK promotes gemcitabine resistance in BTC by regulating EMT.

Midkine induces EMT by upregulating Notch-1 expression. The Notch pathway has a significant role in EMT of cancer cells $(35,36)$, and Notch-1 activation has been reported to be linked to acquired chemoresistance in several cancer types (37-40). Therefore, the role of MDK in Notch-1 expression was then examined in the present study. The western blot results demonstrated that MDK significantly promoted the expression of Notch-1 in BTC cell lines (Fig. 6A). Subsequently, the expression of E-cadherin and vimentin was examined in BTC cells treated with Notch-1 siRNA or a combination of Notch-1 siRNA and MDK. The results indicated that siRNA-mediated knockdown of Notch-1 completely abolished the regulatory effect of MDK on the expression of E-cadherin and vimentin in BTC cells (Fig. 6B). The interference efficiency of Notch1 was detected by western blot analysis (Fig. 6C). These results indicate that Notch-1 is a mediator in MDK-induced EMT.

\section{Discussion}

Chemotherapy has been considered an effective adjuvant therapy for BTC; however, drug resistance limits the efficiency of chemotherapy $(7,41)$. Therefore, further studies are required to determine the potential mechanism of drug resistance in BTC. In the present study, MDK was demonstrated to induce drug resistance in BTC via induction of the EMT through regulating the expression of the Notch-1 protein.

MDK is a growth factor that was first identified as a mediator of retinoic acid-induced differentiation (12). Further studies indicated that it was associated with drug resistance. Mirkin et al (19) proved that MDK was secreted 
A
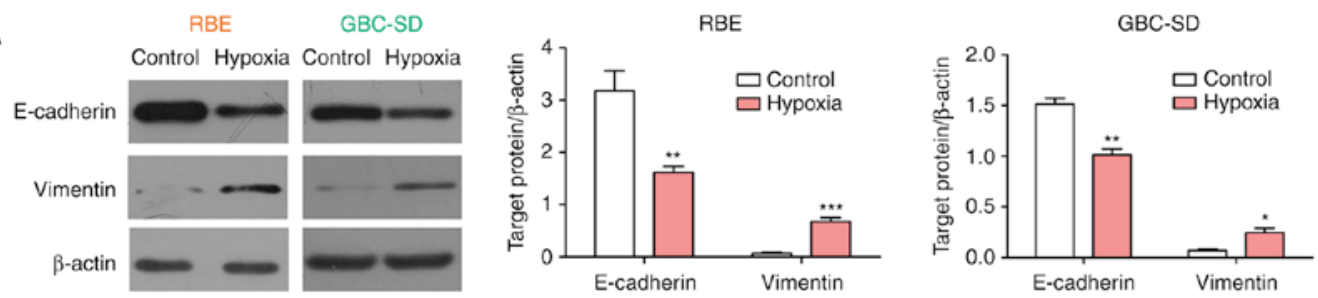

B
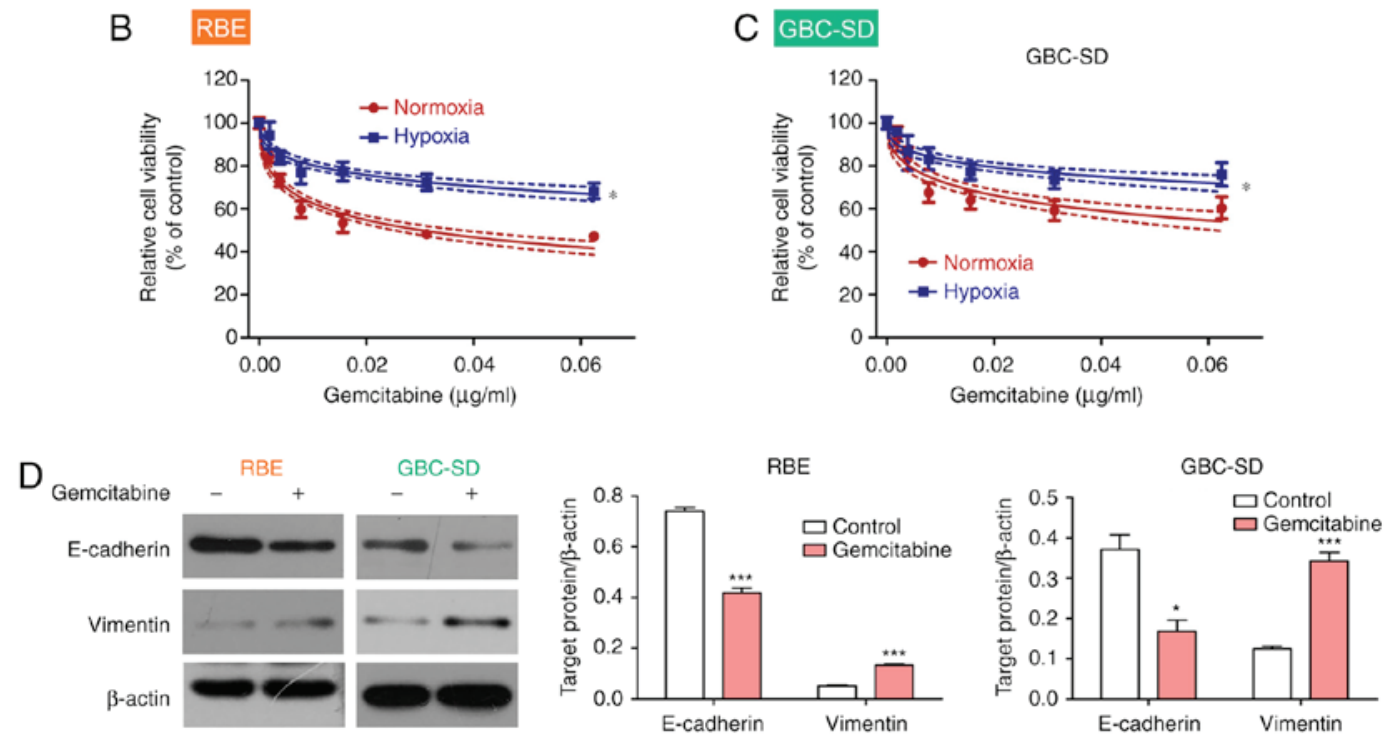

E

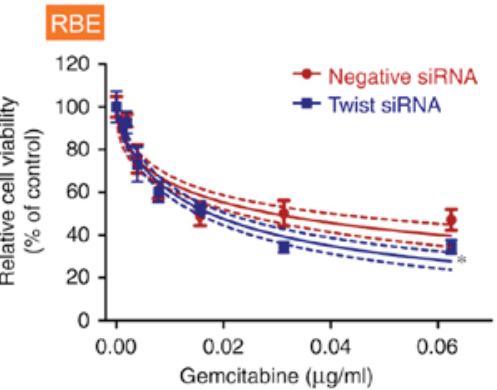

\section{F GBC-SD}
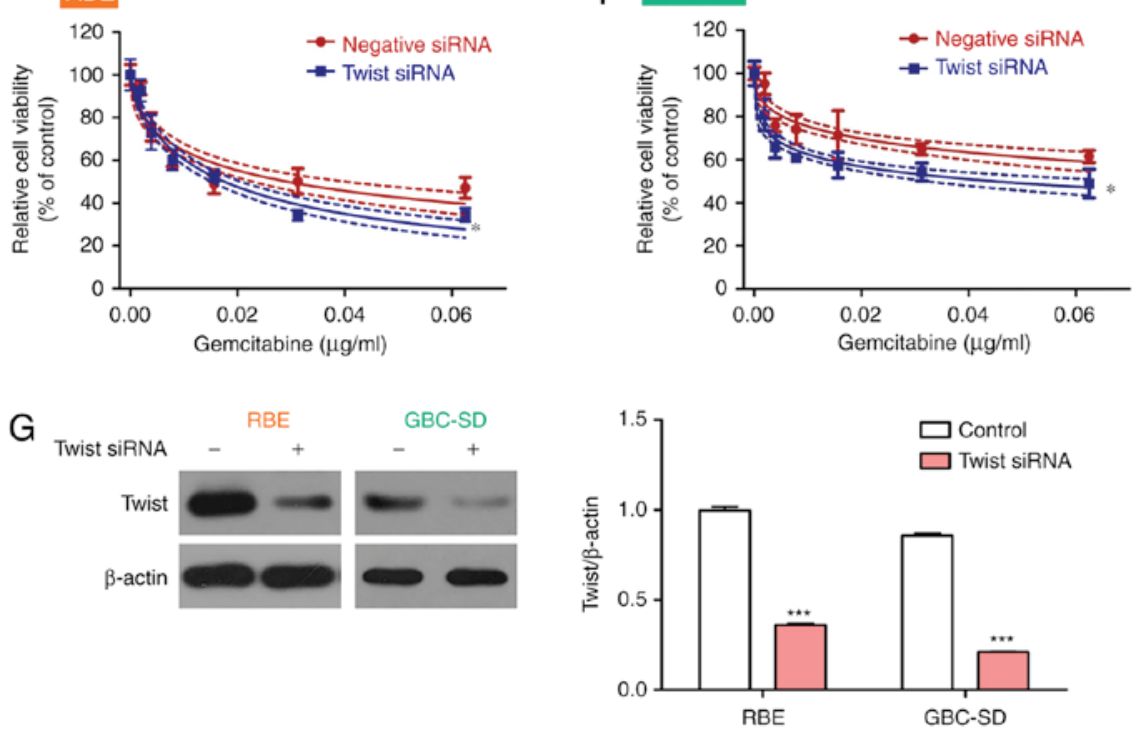

Figure 3. Effect of hypoxia and gemcitabine on the expression of E-cadherin and vimentin in biliary tract cancer cell lines. (A) Comparison of the protein expression of E-cadherin and vimentin under hypoxia and normoxia by western blot analysis. $\beta$-actin was used as the internal control, and the average grey values are presented in a histogram. ${ }^{*} \mathrm{P}<0.05,{ }^{* *} \mathrm{P}<0.01,{ }^{* * *} \mathrm{P}<0.001$ vs. Control. Comparison of the viability of (B) RBE and (C) GBC-SD cells cultured with different concentrations of gemcitabine under hypoxic and normoxic conditions, examined by the Cell Counting Kit-8 assay. ${ }^{*} \mathrm{P}<0.05$ vs. Normoxia. (D) The effect of gemcitabine on the protein expression of E-cadherin and vimentin in GBC-SD and RBE cell lines under normoxia condition was determined by western blot analysis. $\beta$-actin was used as the internal control, and the average grey values are presented in a histogram. ${ }^{*} \mathrm{P}<0.05,{ }^{* * * *} \mathrm{P}<0.001 \mathrm{vs}$. Control. Comparison of viability of (E) RBE and (F) GBC-SD cells treated with Twist siRNA or negative siRNA cultured with different concentrations of gemcitabine. ${ }^{*} \mathrm{P}<0.05$ vs. negative siRNA. (G) Western blot analysis was used to detect the interference efficiency of Twist $1 .{ }^{* * *} \mathrm{P}<0.001$ vs. Control.

from drug-resistant cells and protected the neighboring drug-sensitive cells from the toxicity of doxorubicin. Kang et al (42) identified $>250$ differentially expressed genes in 5-fluorouracil-, cisplatin- or doxorubicin-resistant gastric cancer cell lines by microarray analysis and determined that MDK was overexpressed in all drug-resistant cell lines. Qi et al (43) reported that MDK protected murine kidney cells and cultured Wilms' tumor cells from cisplatin-induced apoptotic cell death by upregulating the expression of B-cell lymphoma 2. Regarding BTC, MDK was upregulated in 

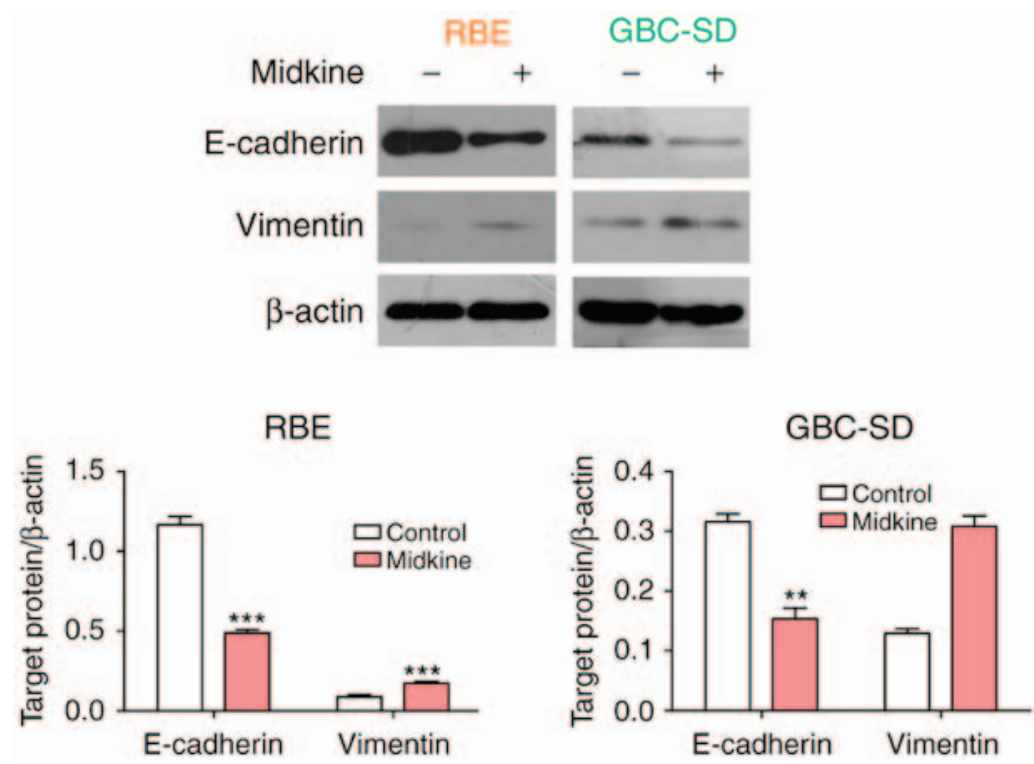

Figure 4. Effect of midkine on the expression of E-cadherin and vimentin. Protein expression of E-cadherin and vimentin in GBC-SD and RBE cell lines with or without midkine determined by western blot analysis. $\beta$-actin was used as the internal control, and the average grey values are presented in the histogram. ${ }^{* *} \mathrm{P}<0.01$ and ${ }^{* * *} \mathrm{P}<0.001$ vs. Control.
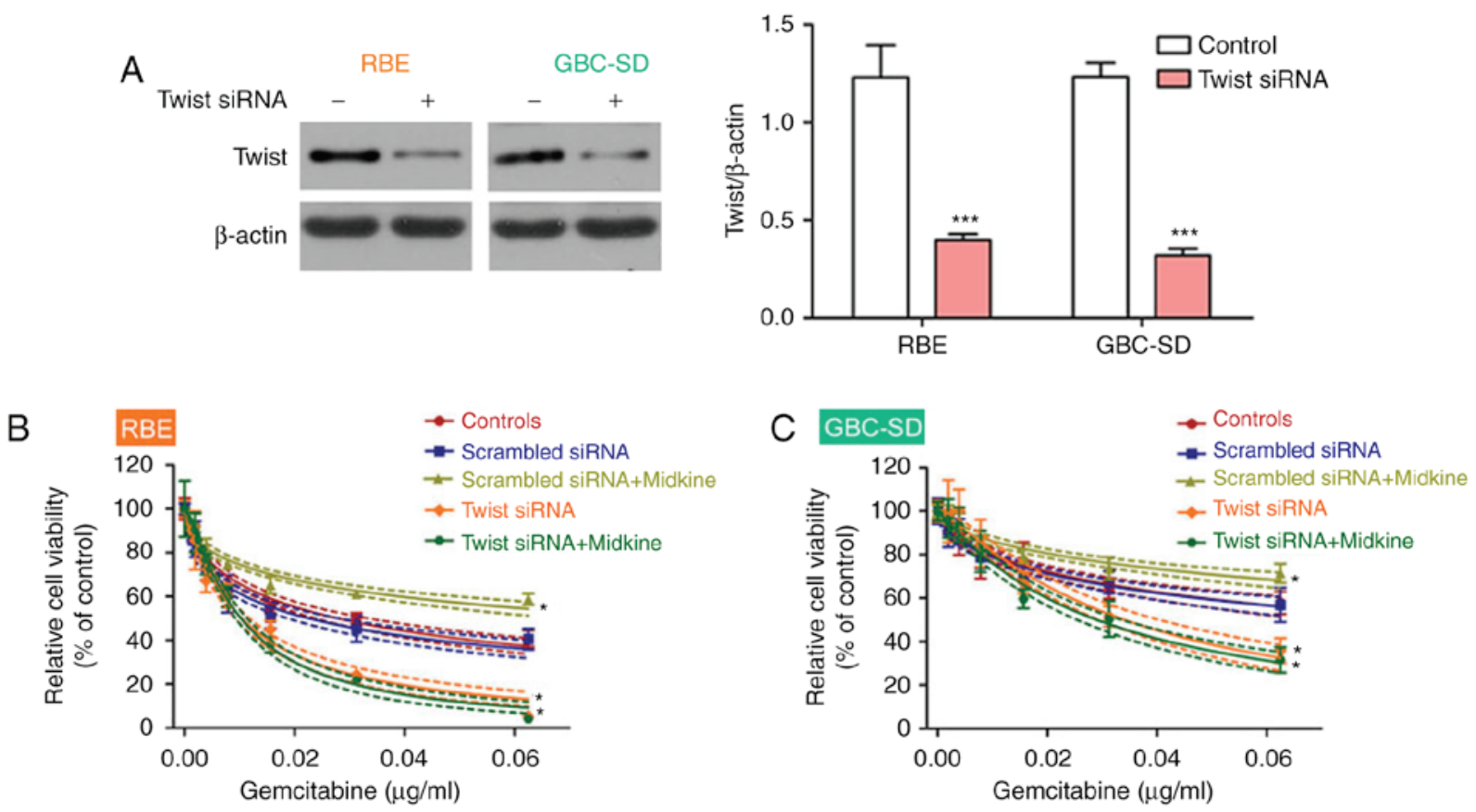

Figure 5. Comparison of the viability of the GBC-SD and RBE cell lines treated with Twist siRNA in the presence of gemcitabine with or without midkine. (A) Examination of the knockdown efficiency of Twist siRNA by western blotting. $\beta$-actin was used as the internal control, and the average grey values are presented in a histogram. ${ }^{* * * *} \mathrm{P}<0.001$ vs. Control. Viability assay of (B) RBE and (C) GBC-SD cells treated with Twist siRNA or scrambled siRNA, gemcitabine and optionally with midkine. ${ }^{*} \mathrm{P}<0.05$ vs. Control.

intrahepatic cholangiocarcinoma. However, little is known regarding the effect of MDK on the drug resistance of BTC. Therefore, the present study assessed this aspect and proved that MDK induced gemcitabine resistance in BTC.

The EMT is known to be involved in cancer drug resistance via various functions, including regulation of cancer cell stemness, overexpression of ATP binding cassette transporters, inhibition of epithelial growth factor receptor tyrosine kinase inhibitor-induced apoptosis and alteration of the tumor microenvironment (44). Previous studies have reported that replication stress-induced MDK expression activates Notch-2, which drives EMT and chemoresistance in pancreatic cancer (30). The MDK-induced crosstalk of Notch2/Janus kinase 2/signal transducer and activator of transcription 3 signaling pathways regulates cell plasticity and motility, thereby contributing to EMT in human keratinocytes (31). In lung adenocarcinoma, estrogen receptor $\beta$-mediated estradiol enhanced MDK expression and increased EMT (29). Considering these previous studies, it was hypothesized that MDK may mediate gemcitabine resistance in BTC cells by regulating EMT. To 


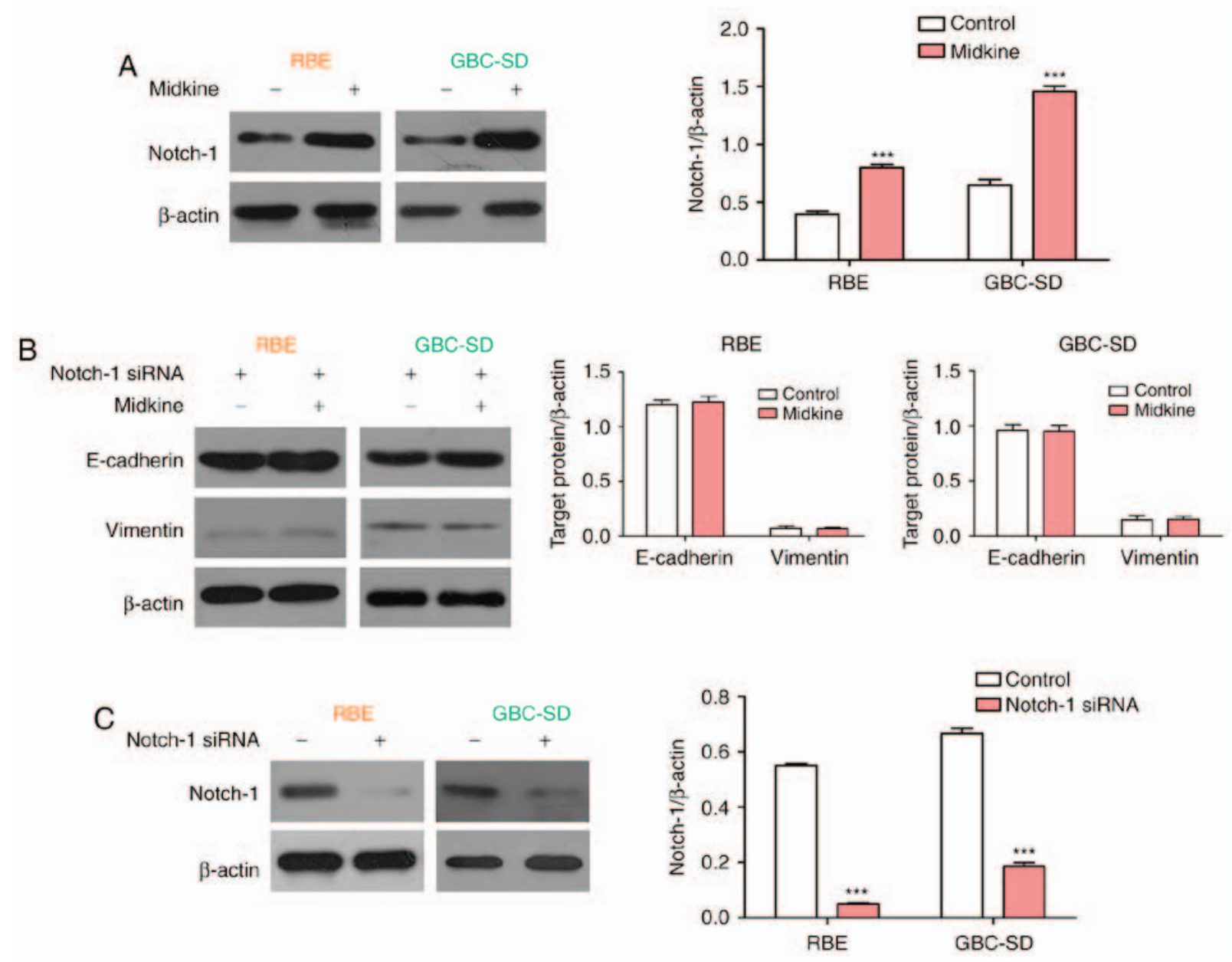

Figure 6. Effect of Notch-1 on midkine-induced epithelial to mesenchymal transition. (A) The protein expression of Notch-1 in GBC-SD and RBE cell lines treated with or without midkine was determined by western blot analysis. ${ }^{* * * *} \mathrm{P}<0.001$ vs. Control. (B) The protein expression of E-cadherin and vimentin in GBC-SD and RBE cell lines treated with Notch-1 siRNA in the presence of midkine was determined by western blot analysis. (C) Western blot analysis was used to detect the interference efficiency of Notch-1. $\beta$-actin was used as the internal control, and the average grey values are presented in a histogram. ${ }^{* * *} \mathrm{P}<0.001 \mathrm{vs}$. Control.

the best of our knowledge, the present study was the first to provide in vitro evidence to prove this hypothesis.

The Notch signaling pathway has critical roles in the development and progression of human cancers, as this pathway is critically involved in numerous cellular processes, including proliferation, survival, apoptosis, migration, invasion, angiogenesis and metastasis. Emerging evidence suggests that Notch regulates EMT, leading to tumor invasion and metastasis $(35,36,45-49)$. Notch-1 has been reported to promote EMT in several cancer types (50-52). Although the association between MDK and Notch-2 is well known, the association between MDK and Notch-1 has remained elusive. In the present study, MDK was demonstrated to upregulate Notch-1 expression and it was revealed that MDK-induced EMT was mediated by Notch-1. These results highlight the role of Notch-1 in MDK-induced EMT.

To the best of our knowledge, the present study was the first to provide evidence that MDK enhances gemcitabine resistance in BTC cells via the Notch-1/EMT axis. Therefore, targeting MDK or blocking/reversing EMT prior to or during chemotherapy may force chemoresistant cells to revert to sensitive cells and may thus provide a tremendous benefit to patients with advanced chemoresistant cancers. Further study is required to understand the precise molecular mechanisms underlying gemcitabine resistance in BTC.

\section{Acknowledgements}

This study was financially supported by the National Natural Science Foundation of China (grant no. 81501830), the Zhejiang Province Natural Science Foundation of China (grant nos. LY16H160041 and LY16H160041) and the Huzhou Science and Technology Project (grant nos. 2014GZ11 and 2015GZ16).

\section{Competing interests}

The authors declare that they have no competing interests.

\section{References}

1. Hennedige TP, Neo WT and Venkatesh SK: Imaging of malignancies of the biliary tract-an update. Cancer Imaging 14: 14, 2014.

2. Randi G, Malvezzi M, Levi F, Ferlay J, Negri E, Franceschi S and La Vecchia C: Epidemiology of biliary tract cancers: An update. Ann Oncol 20: 146-159, 2009.

3. Horgan AM, Amir E, Walter T and Knox JJ: Adjuvant therapy in the treatment of biliary tract cancer: A systematic review and meta-analysis. J Clin Oncol 30: 1934-1940, 2012.

4. Hezel AF and Zhu AX: Systemic therapy for biliary tract cancers. Oncologist 13: 415-423, 2008. 
5. Khan SA, Davidson BR, Goldin RD, Heaton N, Karani J,Pereira SP, Rosenberg WM, Tait P, Taylor-Robinson SD, Thillainayagam AV, et al: Guidelines for the diagnosis and treatment of cholangiocarcinoma: An update. Gut 61: 1657-1669, 2012.

6. Goyal L, Chong DQ, Duda DG and Zhu AX: Chemotherapy and antiangiogenics in biliary tract cancer. Lancet Oncol 16 : $882-883,2015$.

7. Ghosn M, Kourie HR, El Rassy E, Chebib R, El Karak F, Hanna C and Nasr D: Optimum chemotherapy for the management of advanced biliary tract cancer. World J Gastroenterol 21 : 4121-4125, 2015

8. Park K, Kim KP, Park S and Chang HM: Comparison of gemcitabine plus cisplatin versus capecitabine plus cisplatin as first-line chemotherapy for advanced biliary tract cancer. Asia Pac J Clin Oncol 13: 13-20, 2017.

9. Stein A, Arnold D, Bridgewater J, Goldstein D, Jensen LH, Klümpen HJ, Lohse AW, Nashan B, Primrose J, Schrum S, et al: Adjuvant chemotherapy with gemcitabine and cisplatin compared to observation after curative intent resection of cholangiocarcinoma and muscle invasive gallbladder carcinoma (ACTICCA-1 trial)-a randomized, multidisciplinary, multinational phase III trial. BMC Cancer 15: 564, 2015.

10. Lamarca A, Benafif S, Ross P, Bridgewater J and Valle JW: Cisplatin and gemcitabine in patients with advanced biliary tract cancer $(\mathrm{ABC})$ and persistent jaundice despite optimal stenting: Effective intervention in patients with luminal disease. Eur J Cancer 51: 1694-1703, 2015.

11. Yonemoto N, Furuse J, Okusaka T, Yamao K, Funakoshi A, Ohkawa S, Boku N, Tanaka K, Nagase M, Saisho H and Sato T: A multi-center retrospective analysis of survival benefits of chemotherapy for unresectable biliary tract cancer. Jpn J Clin Oncol 37: 843-851, 2007.

12. Böhlen P and Kovesdi I: HBNF and MK members of a novel gene family of heparin-binding proteins with potential roles in embryogenesis and brain function. Prog Growth Factor Res 3: 143-157, 1991.

13. Vu Van D, Heberling U, Wirth MP and Fuessel S: Validation of the diagnostic utility of urinary midkine for the detection of bladder cancer. Oncol Lett 12: 3143-3152, 2016.

14. Edfeldt K, Daskalakis K, Bäcklin C, Norlén O, Tiensuu Janson E, Westin G, Hellman P and Stålberg P: DcR3, TFF3 and midkine are novel serum biomarkers in small intestinal neuroendocrine tumors. Neuroendocrinology 105: 170-181, 2017.

15. Krzystek-Korpacka M, Gorska S, Diakowska D, Kapturkiewicz B Podkowik M, Gamian A and Bednarz-Misa I: Midkine is up-regulated in both cancerous and inflamed bowel, reflecting lymph node metastasis in colorectal cancer and clinical activity of ulcerative colitis. Cytokine 89: 68-75, 2017.

16. Vongsuvanh R, van der Poorten D, Iseli T, Strasser SI, McCaughan GW and George J: Midkine increases diagnostic yield in AFP negative and NASH-related hepatocellular carcinoma. PLoS One 11: e0155800, 2016.

17. Yamashita T, Shimada H, Tanaka S, Araki K, Tomifuji M, Mizokami D, Tanaka N, Kamide D, Miyagawa Y, Suzuki H, et al: Serum midkine as a biomarker for malignancy, prognosis, and chemosensitivity in head and neck squamous cell carcinoma. Cancer Med 5: 415-425, 2016.

18. Yao J, Li WY and Gao SG: The advances of Midkine with peripheral invasion in pancreatic cancer. Am J Cancer Res 5: 2912-2917, 2015

19. Mirkin BL, Clark S, Zheng X, Chu F, White BD, Greene M and Rebbaa A: Identification of midkine as a mediator for intercellular transfer of drug resistance. Oncogene 24: 4965-4974, 2005.

20. Lorente M,Torres S,Salazar M,Carracedo A,Hernández-TiedraS Rodríguez-Fornés F, García-Taboada E, Meléndez B, Mollejo M, Campos-Martín Y, et al: Stimulation of ALK by the growth factor midkine renders glioma cells resistant to autophagy-mediated cell death. Autophagy 7: 1071-1073, 2011.

21. Xu YY, Mao XY, Song YX, Zhao F, Wang ZN, Zhang WX, $\mathrm{Xu} \mathrm{HM}$ and Jin F: Midkine confers Adriamycin resistance in human gastric cancer cells. Tumor Biol 33: 1543-1548, 2012

22. Hu R, Yan Y, Li Q, Lin Y, Jin W, Li H, Lu Y and Pang T: Increased drug efflux along with midkine gene high expression in childhood B-lineage acute lymphoblastic leukemia cells. Int J Hematol 92: 105-110, 2010.

23. Vaquero J, Guedj N, Clapéron A, Nguyen Ho-Bouldoires TH Paradis V and Fouassier L: Epithelial-mesenchymal transition in cholangiocarcinoma: From clinical evidence to regulatory networks. J Hepatol 66: 424-441, 2017.
24. Sung WJ, Kim H and Park KK: The biological role of epithelial-mesenchymal transition in lung cancer (Review). Oncol Rep 36: 1199-1206, 2016.

25. Nomura A, Majumder K, Giri B, Dauer P, Dudeja V, Roy S, Banerjee S and Saluja AK: Inhibition of NF-kappa B pathway leads to deregulation of epithelial-mesenchymal transition and neural invasion in pancreatic cancer. Lab Invest 96: 1268-1278, 2016.

26. Kim HS, Lee KS, Bae HJ, Eun JW, Shen Q, Park SJ, Shin WC, Yang HD, Park M, Park WS, et al: MicroRNA-31 functions as a tumor suppressor by regulating cell cycle and epithelial-mesenchymal transition regulatory proteins in liver cancer. Oncotarget 6 : 8089-8102, 2015

27. Zhang X, Liu X, Luo J, Xiao W, Ye X, Chen M, Li Y and Zhang GJ: Notch3 inhibits epithelial-mesenchymal transition by activating Kibra-mediated Hippo/YAP signaling in breast cancer epithelial cells. Oncogenesis 5: e269, 2016.

28. Xu G, Shao G, Pan Q, Sun L, Zheng D and Li M: MicroRNA-9 regulates non-small cell lung cancer cell invasion and migration by targeting eukaryotic translation initiation factor $5 \mathrm{~A} 2$. Am J Transl Res 9: 478-488, 2017.

29. Zhao G, Nie Y, Lv M, He L, Wang T and Hou Y: ER $\beta$-mediated estradiol enhances epithelial mesenchymal transition of lung adenocarcinoma through increasing transcription of midkine. Mol Endocrinol 26: 1304-1315, 2012.

30. Güngör C, Zander H, Effenberger KE, Vashist YK, Kalinina T, Izbicki JR, Yekebas E and Bockhorn M: Notch signaling activated by replication stress-induced expression of midkine drives epithelial-mesenchymal transition and chemoresistance in pancreatic cancer. Cancer Res 71: 5009-5019, 2011.

31. Huang Y, Hoque MO, Wu F, Trink B, Sidransky D and Ratovitski EA: Midkine induces epithelial-mesenchymal transition through Notch2/Jak2-Stat3 signaling in human keratinocytes. Cell Cycle 7: 1613-1622, 2008.

32. Chen S, Chen JZ, Zhang JQ, Chen HX, Yan ML, Huang L, Tian YF, Chen YL and Wang YD: Hypoxia induces TWIST-activated epithelial-mesenchymal transition and proliferation of pancreatic cancer cells in vitro and in nude mice. Cancer Lett 383: 73-84, 2016.

33. Yang J, Zhang X, Zhang Y, Zhu D, Zhang L, Li Y, Zhu Y, Li D and Zhou J: HIF-2 $\alpha$ promotes epithelial-mesenchymal transition through regulating Twist2 binding to the promoter of E-cadherin in pancreatic cancer. J Exp Clin Cancer Res 35: 26 , 2016.

34. Lee JY and Kong G: Roles and epigenetic regulation of epithelial-mesenchymal transition and its transcription factors in cancer initiation and progression. Cell Mol Life Sci 73: 4643-4660, 2016.

35. Espinoza I, Pochampally R, Xing F, Watabe $K$ and Miele L: Notch signaling: Targeting cancer stem cells and epithelial-to-mesenchymal transition. Onco Targets Ther 6: 1249-1259, 2013

36. Ma J, Xia J, Miele L, Sarkar FH and Wang Z: Notch signaling pathway in pancreatic cancer progression. Pancreat Disord Ther 3: pii: 1000114, 2013.

37. Liu H, Yin Y, Hu Y, Feng Y, Bian Z, Yao S, Li M, You Q and Huang Z: miR-139-5p sensitizes colorectal cancer cells to 5-fluorouracil by targeting NOTCH-1. Pathol Res Pract 212: 643-649, 2016.

38. Mirone G, Perna S, Shukla A and Marfe G: Involvement of Notch-1 in resistance to regorafenib in colon cancer cells. J Cell Physiol 231: 1097-1105, 2016.

39. Xie M, He CS, Wei SH and Zhang L: Notch-1 contributes to epidermal growth factor receptor tyrosine kinase inhibitor acquired resistance in non-small cell lung cancer in vitro and in vivo. Eur J Cancer 49: 3559-3572, 2013

40. Osipo C, Patel P, Rizzo P, Clementz AG, Hao L, Golde TE and Miele L: ErbB-2 inhibition activates Notch-1 and sensitizes breast cancer cells to a gamma-secretase inhibitor. Oncogene 27: 5019-5032, 2008

41. Oyasiji T, Zhang J, Kuvshinoff B, Iyer R and Hochwald SN: Molecular targets in biliary carcinogenesis and implications for therapy. Oncologist 20: 742-751, 2015.

42. Kang HC, Kim IJ, Park JH, Shin Y, Ku JL, Jung MS, Yoo BC, Kim HK and Park JG: Identification of genes with differential expression in acquired drug-resistant gastric cancer cells using high-density oligonucleotide microarrays. Clin Cancer Res 10: 272-284, 2004

43. Qi M, Ikematsu S, Ichihara-Tanaka K, Sakuma S, Muramatsu T and Kadomatsu K: Midkine rescues Wilms' tumor cells from cisplatin-induced apoptosis: Regulation of Bcl-2 expression by Midkine. J Biochem 127: 269-277, 2000. 
44. Du B and Shim JS: Targeting epithelial-mesenchymal transition (EMT) to overcome drug resistance in cancer. Molecules 21: pii: E965, 2016.

45. Brabletz S, Bajdak K, Meidhof S, Burk U, Niedermann G, Firat E, Wellner U, Dimmler A, Faller G, Schubert J and Brabletz T: The ZEB1/miR-200 feedback loop controls Notch signalling in cancer cells. EMBO J 30: 770-782, 2011.

46. Espinoza I and Miele L: Deadly crosstalk: Notch signaling at the intersection of EMT and cancer stem cells. Cancer Lett 341: 41-45, 2013.

47. Hu YY, Zheng MH, Zhang R, Liang YM and Han H: Notch signaling pathway and cancer metastasis. Adv Exp Med Biol 727: 186-198, 2012.

48. Vinson KE, George DC, Fender AW, Bertrand FE and Sigounas G: The Notch pathway in colorectal cancer. Int J Cancer 138: 1835-1842, 2016.

49. Wang Z, Li Y, Banerjee S and Sarkar FH: Emerging role of Notch in stem cells and cancer. Cancer Lett 279: 8-12, 2009.

50. Bao B, Wang Z, Ali S, Kong D, Li Y, Ahmad A, Banerjee S, Azmi AS, Miele L and Sarkar FH: Notch-1 induces epithelial-mesenchymal transition consistent with cancer stem cell phenotype in pancreatic cancer cells. Cancer Lett 307: 26-36, 2011.
51. Fender AW, Nutter JM, Fitzgerald TL, Bertrand FE and Sigounas G: Notch-1 promotes stemness and epithelial to mesenchymal transition in colorectal cancer. J Cell Biochem 116: 2517-2527, 2015

52. Hao L, Rizzo P, Osipo C, Pannuti A, Wyatt D, Cheung LW, Sonenshein G, Osborne BA and Miele L: Notch-1 activates estrogen receptor-alpha-dependent transcription via IKK alpha in breast cancer cells. Oncogene 29: 201-213, 2010.

This work is licensed under a Creative Commons Attribution-NonCommercial-NoDerivatives 4.0 International (CC BY-NC-ND 4.0) License. 